\title{
Climacteric
}

\section{Impact of endogenous and exogenous progesterone exposure on stress biomarkers: a systematic review}

\section{A. Stadler, S. Weidlinger \& P. Stute}

To cite this article: A. Stadler, S. Weidlinger \& P. Stute (2019) Impact of endogenous and exogenous progesterone exposure on stress biomarkers: a systematic review, Climacteric, 22:5, 435-441, DOI: $10.1080 / 13697137.2019 .1622085$

To link to this article: https://doi.org/10.1080/13697137.2019.1622085

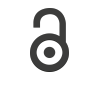

(c) 2019 The Author(s). Published by Informa

UK Limited, trading as Taylor \& Francis Group.

View supplementary material $₫$

曲 Published online: 03 Jul 2019.

Submit your article to this journal ๔

Џll Article views: 431

Q View related articles $\square$

View Crossmark data ¿ 


\title{
Impact of endogenous and exogenous progesterone exposure on stress biomarkers: a systematic review
}

\author{
A. Stadler, S. Weidlinger and P. Stute \\ Department of Obstetrics and Gynecology, Inselspital, University Clinic of Bern, Bern, Switzerland
}

ABSTRACT

Stress activates the autonomic nervous system (ANS) and the hypothalamic-pituitary-adrenal axis (HPAA). Based on a systematic literature review of the impact of endogenous and exogenous exposure with natural progesterone on the stress response in healthy premenopausal and postmenopausal women, the following conclusions can be drawn: the HPAA activity was not relevantly affected by endogenous progesterone exposure across the menstrual cycle, but might be reduced by exogenous micronized progesterone application; in contrast, the ANS has a sympathetic predominance in the (progesterone-dominated) luteal phase of the menstrual cycle. Future studies should assess various stress biomarkers under various hormonal conditions to, for example, allow for cardiovascular risk stratification in hormone users.
ARTICLE HISTORY

Received 2 May 2019

Accepted 14 May 2019

Published online 3 July 2019

\section{KEYWORDS}

Heart rate variability; hypothalamicpituitary-adrenal axis; cortisol; progesterone; menstrual cycle; menopause; menopausal hormone therapy

\section{Introduction}

Stress is the body's response to intrinsic or extrinsic positive or negative challenging factors. Acute stress reactions last for minutes or hours, whereas chronic stress is defined as maladjustment to repeatedly occurring stressors due to the absence of appropriate coping mechanisms ${ }^{1}$ lasting for days to months ${ }^{2}$. Stressors activate the autonomic nervous system (ANS) and hypothalamic-pituitary-adrenal axis (HPAA) ${ }^{3}$.

Non-invasive measurement of heart rate variability (HRV) that is, the ongoing beat-to-beat variation of cyclic heart activity $^{4}$ - is an established method to assess the autonomic balance $^{5}$ and to characterize ANS reactivity ${ }^{6}$. Reduced HRV implies less ANS adaptability and has been found to be associated with increased cardiovascular disease morbidity ${ }^{7}$ and mortality ${ }^{8}$. Both elevated sympathetic and decreased parasympathetic activity tend to aggravate arrhythmias leading to death ${ }^{9}$. There are two common ways to measure HRV: time domain analysis and frequency domain analysis (Tables 1 and 2) ${ }^{10}$.

Cortisol is the executive hormone after HPAA stimulation aiming to provide sufficient energy to overcome stress factors $^{11}$ by, for example, encouraging catabolic pathways as proteolysis and lipolysis, raising plasma concentrations of glucose, free fatty acid, and insulin ${ }^{12}$, and modulating the immune system ${ }^{13}$. Cortisol levels can be measured in plasma, serum, saliva, and urine. The unbound cortisol fraction represents the physiological reactive cortisol amount. Unbound salivary and urinary cortisol levels are strongly correlated and better represent adrenocortical function than the total cortisol serum level, which mainly represents protein-bound cortisol $^{11,14}$. In contrast, approximately only $14 \%$ of salivary and $1 \%$ of urinary cortisol is protein bound ${ }^{11}$.

Especially, chronic stress exposure is associated with an increased risk for several chronic non-communicable diseases such as cardiovascular diseases ${ }^{15}$, gastrointestinal diseases ${ }^{16}$, diabetes mellitus, osteoporosis, immunodeficiency ${ }^{17}$, sleeping disorders ${ }^{18}$, and chronic pain ${ }^{19}$. In women, the noncommunicable disease risk also increases after menopause and may be attenuated or even prevented by menopausal hormone therapy $(\mathrm{MHT})^{20}$. Indeed, endogenous sex hormones have been shown to have an impact on the $\mathrm{ANS}^{21-23}$ and the HPAA ${ }^{24}$. Similarly, in postmenopausal women MHT has been found to beneficially modify the stress response ${ }^{22,25}$.

The aim of this systematic review was to investigate the impact of endogenous (menstrual cycle) and exogenous (MHT containing micronized progesterone [MP]) progesterone $(P)$ exposure on stress biomarkers, cortisol, and HRV, respectively.

\section{Materials and methods}

In November 2018, a systematic literature search was performed using the Medline database (PubMed). Only articles in English and studies in humans were included.

CONTACT Petra Stute petra.stute@insel.ch Department of Gynecologic Endocrinology and Reproductive Medicine, University Clinic of Obstetrics and Gynecology, Inselspital, Bern, Friedbühlstrasse 19, 3010 Bern, Switzerland

(4) Supplemental data for this article can be accessed here.

(C) 2019 The Author(s). Published by Informa UK Limited, trading as Taylor \& Francis Group.

This is an Open Access article distributed under the terms of the Creative Commons Attribution-NonCommercial-NoDerivatives License (http://creativecommons.org/licenses/by-nc-nd/4.0/), which permits non-commercial re-use, distribution, and reproduction in any medium, provided the original work is properly cited, and is not altered, transformed, or built upon in any way. 
Table 1. Selected time domain parameters of heart rate variability.

\begin{tabular}{|c|c|}
\hline Parameter (unit) & Description \\
\hline SDNN (ms) & $\begin{array}{l}\text { Standard deviation of all normal sinus beat intervals }{ }^{9} \text {; representing the balance of sympathetic and parasympathetic activity, a } \\
\text { reduction implies a diminished vagal activity }{ }^{61}\end{array}$ \\
\hline SDANN (ms) & $\begin{array}{l}\text { Standard deviation of the averages of normal sinus beat intervals in all 5-min segments along the whole } \\
\text { electrocardiogram recording }\end{array}$ \\
\hline SDNN index (ms) & $\begin{array}{l}\text { Mean of the standard deviations of all normal sinus beat intervals for all 5-min segments along the whole } \\
\text { electrocardiogram recording }\end{array}$ \\
\hline RMSSD (ms) & $\begin{array}{l}\text { The square root of the mean of the sum of the squared differences between adjoining normal sinus beat intervals }{ }^{9} \text {; reflecting the } \\
\text { parasympathetic part of autonomic nervous system }{ }^{61}\end{array}$ \\
\hline NN50 count & Number of pairs of adjoining normal sinus beat intervals deviating by more than 50 ms along the whole recording ${ }^{9}$ \\
\hline pNN50 (\%) & $\begin{array}{l}\text { NN50 count divided by the total number of all normal sinus beat intervals }{ }^{9} \text {; reflecting the parasympathetic part of autonomic } \\
\text { nervous system }\end{array}$ \\
\hline
\end{tabular}

Table 2. Selected frequency domain parameters of heart rate variability.

\begin{tabular}{ll}
\hline Parameter (unit) & \multicolumn{1}{c}{ Description } \\
\hline $\operatorname{ULF}\left(\mathrm{ms}^{2}\right)$ & Power in ultra-low-frequency spectrum $(\leq 0.003 \mathrm{~Hz})^{9}$ \\
$\operatorname{VLF}\left(\mathrm{ms}^{2}\right)$ & Power in very-low-frequency spectrum $(0.003-0.04 \mathrm{~Hz})^{9}$ \\
$\mathrm{LF}\left(\mathrm{ms}^{2}\right)$ & Power in low-frequency spectrum $(0.04-0.15 \mathrm{~Hz})^{9} ;$ representing the sympathetic and parasympathetic influence ${ }^{62}$ \\
LF norm (n.u.) & Low-frequency power in normalized units \\
HF $\left(\mathrm{ms}^{2}\right)$ & Power in high-frequency spectrum $(0.15-0.4 \mathrm{~Hz}) ;$ representing the impact of parasympathetic part on the autonomic nervous system ${ }^{62}$ \\
$\mathrm{HF}$ norm (n.u.) & High-frequency power in normalized units \\
LF/HF ratio & Representing balance of sympathetic and parasympathetic activity ${ }^{63}$ \\
Total power $\left(\mathrm{ms}^{2}\right)$ & Variance of all normal sinus beat intervals (approximately $\leq 0.4 \mathrm{~Hz})^{9} ;$ reflecting the complete activity of the autonomic nervous system ${ }^{62}$ \\
\hline
\end{tabular}

As MP has been available in Europe since $1980^{26}$ and worldwide since $1986^{27}$, only articles published after 1980 were included. For each topic - that is, impact of endogenous $\mathrm{P}$ and exogenous MP on the HPAA and HRV - individual searches were performed using multiple combinations of keywords, Mesh terms, and text words related to the respective topic. For the first topic, included keywords were the MeSH terms 'corticotropin-releasing hormone', 'adrenocorticotropic hormone', and 'cortisol' and its keywords using the logical connection OR. The resulting hits were connected to the MeSH terms 'progesterone', 'hormone replacement therapy', and 'menstrual cycle' and its keywords using the logical connection AND. To restrict the number of hits to those with the highest scientific evidence level, only meta-analyses, systematic reviews, and randomized controlled trials (RCTs) were included. For the second topic, the MeSH terms 'heart rate variability' were linked with 'progesterone', 'hormone replacement therapy', and 'menstrual cycle' and its keywords using the logical connection AND. Assuming that the review by von Holzen et al. ${ }^{22}$ was complete, only articles published after 2015 were considered for all search commands with 'heart rate variability'. Exclusion criteria were other medications expected for MHT not containing MP that may influence the HPA or the ANS, respectively. Similarly studies without clear identification of progestogen type were excluded.

\section{Results}

Out of 321 hits, 41 articles fulfilled the inclusion and exclusion criteria and were included in the review (Table 3 ).
Impact of progesterone on the

hypothalamic-pituitary-adrenal axis

Impact of endogenous progesterone exposure across the menstrual cycle on the hypothalamic-pituitary-adrenal axis

Overall, 19 studies evaluated the impact of endogenous $P$ exposure across the menstrual cycle on the HPAA $3,14,28-44$ (Supplementary Table S1). Of those, 12 studies assessed baseline HPAA serum level $\left.\right|^{3,14,29,31-34,36-38,40,43}$, and 12 studies assessed HPAA reactivity after a challenge test $^{3,14,28-30,35,36,39,41-44}$. All but three articles were RCTs, while two were systematic reviews ${ }^{31,43}$ and one was an observational cohort study ${ }^{3}$. The sample size ranged from five ${ }^{35}$ to $56^{29}$ subjects. Mean age ranged from 20.7 years ${ }^{38}$ to 36.6 years $^{42}$, or was not clearly specified ${ }^{29,44}$. Participants were neither pregnant nor users of hormonal contraceptives and were generally healthy in all but two studies including women with premenstrual syndrome $(\mathrm{PMS})^{36,43}$ or premenstrual dysphoric disorder (PMDD) ${ }^{42}$, respectively. One study did not report subjects' health condition ${ }^{34}$.

Assessments of the baseline HPAA serum level comprised at least one cortisol serum sample during the follicular phase and another during the luteal phase of the menstrual cycle in most studies $30,32,33,35,36,39-44$. Others used salivary cortisol $^{28,29,33,34,37,43}$, urinary cortisol ${ }^{14,38,43}$, adrenocorticotropic hormone (ACTH) serum ${ }^{30,43}$, or corticotropinreleasing hormone $(\mathrm{CRH})$ samples $^{31}$, respectively. Cortisol levels were measured by various methods including radioimmunoassay ${ }^{14,30,32,38-42,44}$, enzyme immunoassay ${ }^{3,28,29,33,37}$, chemiluminescent immunoassay ${ }^{33,35}$, time-resolved fluorometric immunoassay ${ }^{34}$, and solid-phase fluoroimmunoassay ${ }^{36}$. ACTH and cortisol samples were mostly taken between 6:00 a.m. and 12:30 p.m. 3,14,32,33,35,38,40,41,44, and others either in the afternoon between 1:00 and 8:00 p.m..$^{28-30,37,38}$ or along 
Table 3. Literature search

\begin{tabular}{|c|c|c|c|c|c|c|}
\hline & HPAA AND progesterone & HPAA AND menstrual cycle & HPAA AND HRT & HRV AND progesterone & HRV AND menstrual cycle & HRV AND HRT \\
\hline Hits $(n)$ & 137 & 81 & 72 & 5 & 21 & 5 \\
\hline
\end{tabular}

HPAA, hypothalamic-pituitary-adrenal axis; HRT, hormone replacement therapy; HRV, heart rate variability.

the entire day ${ }^{34,38}$. The remaining studies did not describe the exact time point of cortisol ${ }^{31,32,36,39,42,43}$ or $\mathrm{CRH}^{31}$ sample collection.

While $\mathrm{CRH}$ secretion has been reported to change across the menstrual cycle displaying a $\mathrm{CRH}^{31}$ or $\mathrm{ACTH}^{45}$ peak, respectively, around the time of ovulation, the majority of studies did not observe a change of baseline cortisol serum $^{3,14,32-34,36,38,40,43}$, salivary ${ }^{14,34,38}$, and urinary ${ }^{14,38}$ levels across the menstrual cycle. These findings support the earlier systematic review from $1994^{43}$ showing no impact of the menstrual cycle on basal serum cortisol ${ }^{46-51}$ and serum ACTH levels ${ }^{52}$. Some studies also showed no difference for the menstrual cycle on basal urinary ${ }^{53}$ and serum ${ }^{45,54}$ cortisol levels ${ }^{55}$ in women with PMS. However, others found higher salivary $^{29}$ and serum cortisol levels during the luteal than follicular phase, or vice versa for salivary ${ }^{33,37}$ 24-h urinary corti$\mathrm{sol}^{38}$. When comparing women with and without PMDD, the mean values of serum cortisol levels were higher during the follicular phase in women with PMDD and higher in the luteal phase in controls ${ }^{40}$.

Twelve studies investigated the HPAA responsiveness to a challenge test in relation to the menstrual cycle and yielded conflicting results $3,14,28-30,35,36,39,41-44$.

In detail, five studies did not report any alterations in HPAA responsiveness due to the menstrual cycle on urin$\operatorname{ary}^{14}$, salivary ${ }^{14}$, and serum cortisol ${ }^{30,35,41,44}$ and serum ACTH levels $^{30}$. In these studies, the following HPAA challenge tests were applied: insulin tolerance test ${ }^{30}$, physical exercise ${ }^{14,35}$, alcohol drink ${ }^{41}$, and different diets ${ }^{44}$. These findings support the earlier systematic review from $1994^{43}$ showing no impact of the menstrual cycle on serum cortisol ${ }^{53,56}$, serum $\mathrm{ACTH}^{53}$, and urinary cortisol $^{57}$ responsiveness. The HPAA challenge tests used were intravenous ovine $\mathrm{CRH}$ injection ${ }^{53}$, psychoneuroendocrine stress ${ }^{57}$, and physical exercise ${ }^{56}$.

In contrast, others reported a higher salivary ${ }^{28}$ and serum $^{39}$ cortisol stress response in the follicular phase as compared to the luteal phase. In these studies, the Trier Social Stress Test $^{28}$, intravenous alcohol injection ${ }^{36}$, an alcohol drink ${ }^{42}$, or a certain diet $^{39}$ were used as HPAA challenge tests.

Quite the opposite was observed by two studies ${ }^{29,39}$ using either a cold pressor stress test ${ }^{29}$ or soy diet ${ }^{39}$ as the HPAA challenge test, respectively. They found a higher salivary ${ }^{29}$ and serum ${ }^{39}$ cortisol stress response in the luteal phase as compared to the follicular phase.

Bringing up one study in particular, Ohara et al. ${ }^{3}$ compared salivary cortisol levels at baseline and after a 14-h fast (fasting trial), respectively, after a 12-h fast followed by a meal intake (meal intake trial) affected by menstrual cycle phases. The data analysis showed higher baseline cortisol levels in the luteal phase and different phase-related enhancement dependent on the time point of sample collection in the fasting trial. On the contrary, there no alteration of baseline cortisol concentration was detected in relation to cycle phases in the meal intake trial and higher cortisol levels after meal intake in all cortisol measurements. Worthy of note, all data for this publication were not statistically analyzed, as they were only mentioned as values in graphics $^{3}$.

Impact of MHT containing micronized progesterone on the hypothalamic-pituitary-adrenal axis

Overall, only two RCTs investigated the impact of MHT containing MP on the HPAA in healthy postmenopausal women $^{58,59}$ (Supplementary Table S2). The sample size ranged from $10^{58}$ to $25^{59}$ participants, and mean age from 54.8 years $^{58}$ to 57.5 years $^{59}$, respectively. In both trials, interventions comprised a continuous combined MHT regimen containing standard-dose estrogens (transdermal estradiol at $50 \mu \mathrm{g} / \mathrm{day}^{58,59}$, oral conjugated equine estrogens at 0 . $625 \mathrm{mg} /$ day $^{59}$ ) and oral MP at $100 \mathrm{mg} /$ day $^{58,59}$. The duration of the intervention ranged from 12 weeks $^{59}$ to 12 months ${ }^{58}$. Basal morning cortisol serum samples were analyzed by radioimmunoassay at baseline and after 1 month $^{58}$, 3 months ${ }^{58,59}, 6$ months, 9 months, and 12 months ${ }^{58}$, respectively. Compared to baseline, short-term MHT (3 months) did not alter basal cortisol serum concentrations ${ }^{59}$, while 6 months of MHT significantly reduced basal cortisol serum concentrations $^{58}$.

\section{Impact of progesterone on heart rate variability}

Impact of endogenous progesterone exposure across the menstrual cycle on heart rate variability

Of 21 hits, 12 studies evaluated the impact of endogenous $P$ exposure across the menstrual cycle on $\mathrm{HRV}^{3,6,10,21,22,60-66}$ (Supplementary Table S3). There were one systematic review ${ }^{22}$, one $\mathrm{RCT}^{62}$, seven prospective observational cohort studies $^{3,6,10,61,64-66}$ and three comparative analyses ${ }^{21,60,63}$.

Sample size ranged from $7^{3}$ to $100^{21}$ participants, and mean age from 19.2 years ${ }^{66}$ to 48.8 years ${ }^{64}$ or age range from 18 to 37 years $^{10,21,61}$, respectively. Women were generally healthy and neither pregnant nor users of hormonal contraception. One study compared perimenopausal women with and without insomnia ${ }^{64}$, one study included women with mild $\mathrm{PMS}^{66}$, and one study did not report subjects' health condition $^{6}$. For inclusion into this review, HRV assessment had to be performed at least once during the follicular phase and once during the luteal phase of the menstrual cycle. The majority of studies recorded HRV parameters for several minutes $3,10,21,60,62-64,66$, while three performed 24-h electrocardiogram recordings ${ }^{6,61,65}$ or analyzed multiple time points during different sleep stages ${ }^{64}$.

The first systematic review from 2016 analyzed 15 studies on cardiac autonomic control with respect to the menstrual 
cycle $^{22}$. Qualitative comparisons between the vast majority of studies demonstrated a decrease of the vagal dominance on the heart from the follicular to the luteal cycle phase.

More recent studies reported comparable results showing overall a predominance of sympathetic activity in the luteal phase $^{3,6,10,21,60,61,66}$ and predominance of parasympathetic activity in the follicular phase ${ }^{10,60}$, respectively. These findings were in the majority independent of the subject's position (supine, seated, standing) ${ }^{60}$. Sleep deprivation has been found to have an impact on cardiac autonomic control, displaying a move to a predominance of parasympathetic activity after ovulation and a predominance of sympathetic activity before ovulation ${ }^{63}$.

However, others did not find any significant differences in cardiac autonomic control between different menstrual cycle phases ${ }^{62,65}$.

Impact of MHT containing micronized progesterone on heart rate variability

So far, there have not been any studies investigating the impact of MHT containing estrogens combined with MP on HRV.

\section{Discussion}

Stress activates the ANS and the HPAA. Sexual steroid hormones have been found to modulate the stress response. The aim of this systematic review was to specifically analyze the impact of endogenous and exogenous exposure with natural $P$ on the stress response. Our systematic review revealed that the HPAA activity was not relevantly affected by endogenous $P$ exposure across the menstrual cycle, but might be reduced by exogenous MP application. In contrast, the ANS has a sympathetic predominance in the (P-dominated) luteal phase and parasympathetic predominance in the follicular phase of the menstrual cycle, but has not yet been evaluated under exogenous MP exposure.

Most studies did not observe an impact of endogenous $P$ exposure on baseline ${ }^{14,32-34,36,38,40,43,46-53,55}$ or stimulated $^{14,30,35,41,43,44,53,56,57}$ HPAA. However, few studies reported higher baseline ${ }^{33,37,38}$ and stimulated ${ }^{28,36,39}$ cortisol levels during the follicular phase, or vice versa, $39,39,45,54$. Varying results may be due to the type of specimen analyzed (serum, saliva, urine) as differing results have been reported when comparing salivary (no change) to 24-h urinary (higher in the follicular phase) cortisol levels ${ }^{38}$, or salivary (higher in the follicular phase) to serum (no change) cortisol levels ${ }^{33}$, respectively. As cortisol is secreted in a circadian pattern, the time point of sampling is crucial. For example, serum cortisol levels have been found in a previous study to be higher during the follicular phase than the luteal phase when comparing samples taken at 8:00 a.m., while there was no difference when comparing 3:00 p.m. samples across the cycle ${ }^{67}$. The studies included in this review had a wide time spectrum for sampling, or did not even mention it ${ }^{31,36,39,42,43}$. Furthermore, as the individual menstrual cycle length varies $^{43}$, a defined cycle day for (serum, saliva, urine) sampling may still yield different interpersonal and intrapersonal results. Serum cortisol levels are also affected by other factors such as cortisol binding globulin serum levels or comorbidities such as diabetes mellitus ${ }^{68}$ and mood disorders ${ }^{69}$. Women recruited for the studies were characterized to be healthy in general, yet differences in medication, body weight, and lifestyle factors (physical activity, alcohol, diet) and sleeping patterns that physiologically change across the menstrual cycle may affect the stress response ${ }^{6}$. Finally, a broad range of different methods to analyze cortisol levels was applied. Two studies ${ }^{58,59}$ evaluated the impact of MHT containing oral MP on the HPAA, with long-term MHT reducing basal serum cortisol levels. Besides duration of MHT application, other factors such as estrogen type (estradiol, conjugated equine estrogens) and mode of application (oral, transdermal) may yield different results. Importantly, MP was not studied as monotherapy but only in combination with estrogens; thus, differentiating between the two sex steroids' impact on cortisol levels was impossible.

With respect to ANS control, most studies reported a parasympathetic dominance in the follicular phase or a sympathetic dominance in the luteal phase of the menstrual cycle ${ }^{6,10,21,60,61,63,64,66,70-81}$. This supports previous findings of an increased prevalence of arrhythmias during the luteal cycle phase ${ }^{82}$. Contradictory results by others might have been due to certain study designs, for example sleep deprivation $^{63}$, or cohorts either differentiating between women with and without $\mathrm{PMS}^{72,76,77,80,81}$ or $\operatorname{not}^{70,71,73-75,78,79,83-85}$. Direct comparisons between studies were also impaired by different HRV assessment methods including varying duration and time point of electrocardiogram recording. So far, no study has reported the impact of MHT containing MP or MP alone on HRV. As previous studies have reported a beneficial effect of MHT on the stress response in postmenopausal women ${ }^{22}$, which was even more pronounced with combined MHT than estrogen-only therapy ${ }^{25}$, we would expect a shift to a vagal tonus at least for MHT combined with MP.

The strength of our review is the systematic literature search differentiating between two stress biomarkers (HPAA, $H R V$ ), and between endogenous and exogenous sex steroid hormone exposure, and restriction to truly natural $P$ exposure. Clearly, our review also has some limitations such as restriction to publications in English, and identification of studies with only small sample sizes and mainly healthy women. Thus, results might be different in bigger cohorts and cannot be transferred to, for example, diseased individuals. Moreover, some data are mentioned without proof for significance $3,33,39,42,60$. Finally, the results out of our review cannot only be attributed to $P$ itself, as the luteal phase is characterized by high levels of both steroid hormones, estradiol and $\mathrm{P}^{43}$. Most interestingly, there have so far been no studies combining the assessment of both stress biomarkers across the menstrual cycle or when applying MHT, respectively. In future, to obtain a broader picture of the impact of steroid sex hormones on the stress response, it would be preferable to assess various stress biomarkers at the same time (e.g. questionnaires, basal and stimulated serum and 
salivary HPAA effectors, HRV under various conditions) to also evaluate their relative impact.

\section{Conclusion}

Stress activates the ANS and the HPAA. Our systematic review revealed that the HPAA activity was not relevantly affected by endogenous $P$ exposure across the menstrual cycle, but might be reduced by exogenous MP application. In contrast, the ANS has a sympathetic predominance in the (P-dominated) luteal phase of the menstrual cycle. Future studies should assess various stress biomarkers under various hormonal conditions to, for example, allow for cardiovascular disease risk stratification in hormone users.

\section{Acknowledgements}

The authors are grateful for the administrative support of J. Wilhem, secretary at the Department of Obstetrics and Gynecology, Inselspital, Bern.

Potential conflict of interest P. Stute has been part of a Germanspeaking expert board funded by DR. KADE/BESINS Pharma GmbH. A. Stadler and S. Weidlinger do not have any conflict of interest. The authors alone are responsible for the content and writing of the article.

Source of funding The publication was not funded.

\section{ORCID}

P. Stute (iD) http://orcid.org/0000-0002-5591-1552

\section{References}

1. Petrowski K, Paul S, Albani C, Brahler E. Factor structure and psychometric properties of the trier inventory for chronic stress (TICS) in a representative German sample. BMC Med Res Methodol 2012; $12: 42$

2. Won E, Kim YK. Stress, the autonomic nervous system, and the immune-kynurenine pathway in the etiology of depression. Curr Neuropharmacol 2016;14:665-73

3. Ohara K, Okita Y, Kouda K, Mase T, Miyawaki C, Nakamura H. Cardiovascular response to short-term fasting in menstrual phases in young women: an observational study. BMC Women's Health 2015;15:67

4. Christ M, Seyffart K, Wehling M. Attenuation of heart-rate variability in postmenopausal women on progestin-containing hormone replacement therapy. Lancet 1999;353:1939-40

5. Zygmunt A, Stanczyk J. Methods of evaluation of autonomic nervous system function. Arch Med Sci 2010;6:11-18

6. Tada $Y$, Yoshizaki T, Tomata $Y$, Yokoyama $Y$, Sunami A, Hida A. The impact of menstrual cycle phases on cardiac autonomic nervous system activity: an observational study considering lifestyle (diet, physical activity, and sleep) among female college students. 2017 J Nutr Sci Vitaminol 63:249-55

7. Hillebrand $S$, Gast KB, de Mutsert R, Swenne CA, Jukema JW, Middeldorp $S$. Heart rate variability and first cardiovascular event in populations without known cardiovascular disease: meta-analysis and dose-response meta-regression. EP Europace 2013;15: 742-9

8. Kleiger RE, Stein PK, Bigger JT Jr. Heart rate variability: measurement and clinical utility. Ann Noninvasive Electrocardiol 2005;10: 88-101

9. Heart rate variability: standards of measurement, physiological interpretation and clinical use. Task Force of the European Society of Cardiology and the North American Society of Pacing and Electrophysiology. Circulation 1996;93:1043-65

10. Brar TK, Singh KD, Kumar A. Effect of different phases of menstrual cycle on heart rate variability (HRV). J Clin Diagn Res 2015;9: CC01-4

11. Hellhammer DH, Wust S, Kudielka BM. Salivary cortisol as a biomarker in stress research. Psychoneuroendocrinology 2009;34: 163-71

12. Dempsher DP, Gann DS, Phair RD. A mechanistic model of ACTHstimulated cortisol secretion. Am J Physiol 1984;246:R587-96

13. Rhen T, Cidlowski JA. Antiinflammatory action of glucocorticoidsnew mechanisms for old drugs. $N$ Engl J Med 2005;353:1711-23

14. Boisseau N, Enea C, Diaz V, Dugué B, Corcuff JB, Duclos M. Oral contraception but not menstrual cycle phase is associated with increased free cortisol levels and low hypothalamo-pituitaryadrenal axis reactivity. J Endocrinol Invest 2013;36:955-64

15. Roohafza $H$, Talaei $M$, Sadeghi $M$, Mackie $M$, Sarafzadegan $N$. Association between acute and chronic life events on acute coronary syndrome: a case-control study. J Cardiovasc Nurs 2010;25: E1-7

16. Schüler J, Dietz F, Kurzlehrbuch Medizinische Psychologie und Soziologie. Stuttgart (Germany): Thieme; 2004

17. Buddeberg C, von Kaenel R, Laederach K. Psychophysiologie. In: Psychosoziale Medizin. Berlin (Germany): Springer; 2004

18. Schulz P, Hellhammer J, Schlotz W. Arbeitsstress, sozialer Stress und Schlafqualitat: Differentielle Effekte unter Berücksichtigung von Alter, Besorgnisneigung und Gesundheit [Work stress, social stress, and sleep quality: differential effects in consideration of age, worry disposition, and health]. Zeitschrift fur Gesundheitspsychologie 2003; 11:1-9

19. Ehrstrom S, Kornfeld D, Rylander E, Bohm-Starke N. Chronic stress in women with localised provoked vulvodynia. J Psychosom Obstet Gynaecol 2009;30:73-9

20. Manson JE, Kaunitz AM. Menopause management-getting clinical care back on track. N Engl J Med 2016;374:803-6

21. Choudhary AK, Alam T, Jiwane R, Kishanrao SS. A comparative analysis of dietary habits on sensory motor association and heart rate variability during menstrual cycle. J Clin Diagn Res 2016;10: CCO4-8

22. von Holzen JJ, Capaldo G, Wilhelm M, Stute P. Impact of endoand exogenous estrogens on heart rate variability in women: a review. Climacteric 2016;19:222-8

23. Brockbank CL, Chatterjee F, Bruce SA, Woledge RC. Heart rate and its variability change after the menopause. Exp Physiol 2000;85: 327-30

24. Kirschbaum C, Kudielka BM, Gaab J, Schommer NC, Hellhammer $\mathrm{DH}$. Impact of gender, menstrual cycle phase, and oral contraceptives on the activity of the hypothalamus-pituitary-adrenal axis. Psychosom Med 1999;61:154-62

25. Farag NH, Nelesen RA, Parry BL, Loredo JS, Dimsdale JE, Mills PJ. Autonomic and cardiovascular function in postmenopausal women: the effects of estrogen versus combination therapy. Am J Obstet Gynecol 2002;186:954-61

26. Lignieres B. Oral micronized progesterone. clinical therapeutics. Clin Ther 1999;21:41-60; discussion 1-2

27. Malik S, Krishnaprasad K. Natural micronized progesterone sustained release (SR) and luteal phase: Role Redefined!! J Clin Diagn Res 2016;10

28. Maki PM, Mordecai KL, Rubin LH, et al. Menstrual cycle effects on cortisol responsivity and emotional retrieval following a psychosocial stressor. Horm Behav 2015;74:201-8

29. Felmingham KL, Fong WC, Bryant RA. The impact of progesterone on memory consolidation of threatening images in women. Psychoneuroendocrinology 2012;37:1896-900

30. Long TD, Ellingrod VL, Kathol RG, Christensen LE, Resch DS, Perry PJ. Lack of menstrual cycle effects on hypothalamic-pituitaryadrenal axis response to insulin-induced hypoglycaemia. Clin Endocrinol (Oxf) 2000;52:781-7 
31. Chrousos GP, Torpy DJ, Gold PW. Interactions between the hypothalamic-pituitary-adrenal axis and the female reproductive system: clinical implications. Ann Intern Med 1998;129:229-40

32. Williamson PM, Buddle ML, Brown MA, Whitworth JA. Ambulatory blood pressure monitoring (ABPM) in the normal menstrual cycle and in women using oral contraceptives. Comparison with conventional blood pressure measurement. Am J Hypertens 1996;9: 953-8

33. Roche DJ, King AC. Sex differences in acute hormonal and subjective response to naltrexone: the impact of menstrual cycle phase. Psychoneuroendocrinology 2015;52:59-71

34. Allen AM, Allen SS, Widenmier J, Al'absi M. Patterns of cortisol and craving by menstrual phase in women attempting to quit smoking. Addict Behav 2009;34:632-5

35. Kraemer RR, Francois M, Webb ND, et al. No effect of menstrual cycle phase on glucose and glucoregulatory endocrine responses to prolonged exercise.[Erratum appears in Eur J Appl Physiol. 2013 Sep;113(9):2409 Note: Daniel Castracane, V [corrected to Castracane, V Daniel]]. Eur J Appl Physiol 2013;113:2401-8

36. Nyberg S, Andersson A, Zingmark E, Wahlström G, Bäckström T, Sundström-Poromaa I. The effect of a low dose of alcohol on allopregnanolone serum concentrations across the menstrual cycle in women with severe premenstrual syndrome and controls. Psychoneuroendocrinology 2005;30:892-901

37. Fukui H, Toyoshima K, Komaki R. Psychological and neuroendocrinological effects of odor of saffron (Crocus sativus). Phytomedicine 2011;18:726-30

38. Symonds CS, Gallagher P, Thompson JM, Young AH. Effects of the menstrual cycle on mood, neurocognitive and neuroendocrine function in healthy premenopausal women. Psychol Med 2004;34: 93-102

39. Brown BD, Thomas W, Hutchins A, Martini MC, Slavin JL. Types of dietary fat and soy minimally affect hormones and biomarkers associated with breast cancer risk in premenopausal women. Nutr Cancer 2002;43:22-30

40. Parry BL, Javeed S, Laughlin GA, Hauger R, Clopton P. Cortisol circadian rhythms during the menstrual cycle and with sleep deprivation in premenstrual dysphoric disorder and normal control subjects. Biol Psychiatry 2000;48:920-31

41. Sarkola T, Makisalo H, Fukunaga T, Eriksson CJ. Acute effect of alcohol on estradiol, estrone, progesterone, prolactin, cortisol, and luteinizing hormone in premenopausal women. Alcoholism Clin Exp Res 1999;23:976-82

42. Bhathena SJ, Berlin E, Judd JT, et al. Selective responses of hormones involved in carbohydrate and lipid metabolism and properties of erythrocyte membranes during the menstrual cycle in premenopausal women consuming moderate amounts of alcohol. Am J Clin Nutr 1995;62:751-6

43. Leibenluft E, Fiero PL, Rubinow DR. Effects of the menstrual cycle on dependent variables in mood disorder research. Arch Gen Psychiatry 1994;51:761-81

44. Bhathena SJ, Berlin E, Judd J, et al. Hormones regulating lipid and carbohydrate metabolism in premenopausal women: modulation by dietary lipids. Am J Clin Nutr 1989;49:752-7

45. Genazzani AR, Lemarchand-Beraud T, Aubert ML, Felber JP. Pattern of plasma ACTH, hGH, and cortisol during menstrual cycle. J Clin Endocrinol Metab 1975;41:431-7

46. Carandente F, Angeli A, Candiani GB, et al. Rhythms in the ovulatory cycle. 1st: prolactin. Chronobiological research group on synthetic peptides in medicine. Chronobiologia 1989;16:35-44

47. Rubinow DR, Hoban MC, Grover GN, et al. Changes in plasma hormones across the menstrual cycle in patients with menstrually related mood disorder and in control subjects. Am J Obstet Gynecol 1988;158:5-11

48. Saxena BN, Dusitsin N, Lazarus L. Human growth hormone (HGH), thyroid stimulating hormone (TSH) and cortisol levels in the serum of menstruating Thai women. J Obstet Gynaecol Br Commonw 1974;81:563-7

49. Schoneshofer M, Wagner GG. Sex differences in corticosteroids in man. J Clin Endocrinol Metab 1977;45:814-7
50. Parker CR, Winkel CA, Rush AJ, Porter JC, MacDonald PC. Plasma concentrations of 11-deoxycorticosterone in women during the menstrual cycle. Obstet Gynecol 1981;58:26-30

51. Heitkemper $M$, Jarrett $M$, Bond EF, Turner P. Gl symptoms, function, and psychophysiological arousal in dysmenorrheic women. Nursing Res 1991;40:20-6

52. Mauri A, Martellotta MC, Melis MR, Caminiti F, Serri F, Fratta W. Plasma alpha-melanocyte-stimulating hormone during the menstrual cycle in women. Horm Res 1990;34:66-70

53. Rabin DS, Schmidt PJ, Campbell G, et al. Hypothalamic-pituitaryadrenal function in patients with the premenstrual syndrome. $J$ Clin Endocrinol Metab 1990;71:1158-62

54. Tersman Z, Collins A, Eneroth P. Cardiovascular responses to psychological and physiological stressors during the menstrual cycle. Psychosom Med 1991;53:185-97

55. Steiner M, Haskett RF, Carroll BJ, Hays SE, Rubin RT. Circadian hormone secretory profiles in women with severe premenstrual tension syndrome. Br J Obstet Gynaecol 1984;91:466-71

56. Kanaley JA, Boileau RA, Bahr JM, Misner JE, Nelson RA. Cortisol levels during prolonged exercise: the influence of menstrual phase and menstrual status. Int J Sports Med 1992;13:332-6

57. Collins A, Eneroth P, Landgren BM. Psychoneuroendocrine stress responses and mood as related to the menstrual cycle. Psychosom Med 1985;47:512-27

58. Pluchino N, Ninni F, Stomati M, et al. One-year therapy with $10 \mathrm{mg} /$ day DHEA alone or in combination with HRT in postmenopausal women: effects on hormonal milieu. Maturitas 2008;59:293-303

59. Shifren JL, Desindes S, Mcllwain M, Doros G, Mazer NA. A randomized, open-label, crossover study comparing the effects of oral versus transdermal estrogen therapy on serum androgens, thyroid hormones, and adrenal hormones in naturally menopausal women. Menopause 2007;14:985-94

60. Abidi S, Nili M, Serna S, Kim S, Hazlett C, Edgell H. Influence of sex, menstrual cycle, and oral contraceptives on cerebrovascular resistance and cardiorespiratory function during Valsalva or standing. J Appl Physiol 2017;123:375-86

61. Yazar S, Yazici M. Impact of menstrual cycle on cardiac autonomic function assessed by heart rate variability and heart rate recovery. Med Princ Pract 2016;25:374-7

62. Matsumoto T, Kimura T, Hayashi T. Aromatic effects of a Japanese citrus fruit-yuzu (Citrus junos Sieb. ex Tanaka)-on psychoemotional states and autonomic nervous system activity during the menstrual cycle: a single-blind randomized controlled crossover study. BioPsychoSocial Med 2016;10:11

63. Huang SC, Wong AM, Ho CW, Weng TP, Cheng SC, Wang JS. Comparison of cardiac autonomic nervous system disturbed by sleep deprivation in sex and menstrual phase. [Erratum appears in Chin J Physiol. 2015 Aug 31;58(4):273]. Chin J Physiol 2015;58:114-23

64. de Zambotti M, Trinder J, Colrain IM, Baker FC. Menstrual cyclerelated variation in autonomic nervous system functioning in women in the early menopausal transition with and without insomnia disorder. Psychoneuroendocrinology 2017;75:44-51

65. Suzuki A, Yoshioka K, Ito S, Naito Y. Assessment of stress and autonomic nervous activity in Japanese female ambulance paramedics working 24-hour shifts. J Occup Health 2016;58:47-55

66. Grrishma B, Gaur GS, Velkumary S, Subramanian SK, Gurunandan $\mathrm{U}$. Assessment of cardiovascular autonomic functions and baroreceptor reactivity in women with premenstrual syndrome. Indian J Physiol Pharmacol 2015;59:148-54

67. Beck RP, Morcos F, Fawcett D, Watanabe M. Adrenocortical function studies during the normal menstrual cycle and in women receiving norethindrone with and without mestranol. Am J Obstet Gynecol 1972;112:364-8

68. Ortiz R, Kluwe B, Odei JB, et al. The association of morning serum cortisol with glucose metabolism and diabetes: the Jackson Heart Study. Psychoneuroendocrinology 2019;103:25-32

69. Capponi V, Carrasco C, Macchiavello S, et al. Depressive symptoms are associated with higher morning plasma cortisol in primary care subjects. Neuro Endocrinol Lett 2018;39:288-93 
70. Vallejo M, Marquez MF, Borja-Aburto VH, Cardenas M, Hermosillo AG. Age, body mass index, and menstrual cycle influence young women's heart rate variability -a multivariable analysis. Clin Auton Res 2005;15:292-8

71. Sato N, Miyake S. Cardiovascular reactivity to mental stress: relationship with menstrual cycle and gender. J Physiol Anthropol 2004;23:215-23

72. Landen $M$, Wennerblom $B$, Tygesen $H$, et al. Heart rate variability in premenstrual dysphoric disorder. Psychoneuroendocrinology 2004;29:733-40

73. Yildirir A, Kabakci G, Akgul E, Tokgozoglu L, Oto A. Effects of menstrual cycle on cardiac autonomic innervation as assessed by heart rate variability. Ann Noninv Electrocard 2001;7:60-3

74. Tenan MS, Brothers RM, Tweedell AJ, Hackney AC, Griffin L. Changes in resting heart rate variability across the menstrual cycle. Psychophysiology 2014;51:996-1004

75. Saeki Y, Atogami F, Takahashi K, Yoshizawa T. Reflex control of autonomic function induced by posture change during the menstrual cycle. J Auton Nerv Syst 1997;66:69-74

76. Matsumoto $\mathrm{T}$, Ushiroyama $\mathrm{T}$, Kimura $\mathrm{T}$, Hayashi $\mathrm{T}$, Moritani $\mathrm{T}$. Altered autonomic nervous system activity as a potential etiological factor of premenstrual syndrome and premenstrual dysphoric disorder. BioPsychoSocial Med 2007;1:24

77. Baker FC, Colrain IM, Trinder J. Reduced parasympathetic activity during sleep in the symptomatic phase of severe premenstrual syndrome. J Psychosom Res 2008;65:13-22
78. McKinley PS, King AR, Shapiro PA, et al. The impact of menstrual cycle phase on cardiac autonomic regulation. Psychophysiology 2009;46:904-11

79. Bai X, Li J, Zhou L, Li X. Influence of the menstrual cycle on nonlinear properties of heart rate variability in young women. $\mathrm{Am} J$ Physiol Heart Circ Physiol 2009;297:H765-74

80. Matsumoto $\mathrm{T}$, Ushiroyama $\mathrm{T}$, Morimura $\mathrm{M}$, et al. Autonomic nervous system activity in the late luteal phase of eumenorrheic women with premenstrual symptomatology. J Psychosom Obstet Gynaecol 2006;27:131-9

81. de Zambotti $M$, Nicholas $C L$, Colrain IM, Trinder JA, Baker FC. Autonomic regulation across phases of the menstrual cycle and sleep stages in women with premenstrual syndrome and healthy controls. Psychoneuroendocrinology 2013;38:2618-27

82. Marchlinski FE, Deely MP, Zado ES. Sex-specific triggers for right ventricular outflow tract tachycardia. Am Heart J 2000;139: 1009-13

83. Princi $T$, Parco $S$, Accardo A, Radillo $O$, De Seta $F$, Guaschino S. Parametric evaluation of heart rate variability during the menstrual cycle in young women. Biomed Sci Instrum 2005;41:340-5

84. Leicht AS, Hirning DA, Allen GD. Heart rate variability and endogenous sex hormones during the menstrual cycle in young women. Exp Physiol 2003;88:441-6

85. Weissman A, Lowenstein L, Tal J, Ohel G, Calderon I, Lightman A. Modulation of heart rate variability by estrogen in young women undergoing induction of ovulation. Eur J Appl Physiol 2009;105:381-6 